\title{
Connection between salinity and light absorption coefficient
}

\author{
Vladimir I. Haltrin, Donald R. Johnson, and Alan D.Weidemann \\ Naval Research Laboratory, Ocean Sciences Branch, Code 7330 \\ Stennis Space Center, MS 39529-5004, USA. \\ Phone: 228-688-4528, fax: 228-688-4189, e-mail: <haltrin@nrlssc.navy.mil>
}

\begin{abstract}
In many important applications it is necessary to estimate inherent optical properties of sea water using only available oceanographic data. Among the many hydrographic parameters of sea water only salinity has been shown to have a significant correlation with such optical parameters such as absorption coefficient. This correlation is due to the coupling between salinity and concentration of dissolved organic matter. The advantages and disadvantages in using this correlation to retrieve absorption properties is examined for a coastal plume.
\end{abstract}

\section{INTRODUCTION}

In order to derive dependencies between absorption coefficient and salinity we used mooring data collected during Cope 97 experiment in Chesapeake Bay. This mooring provided a large number of data points that allowed a correlation between salinity and optical properties for the effluent plume to be determined. The correlation between

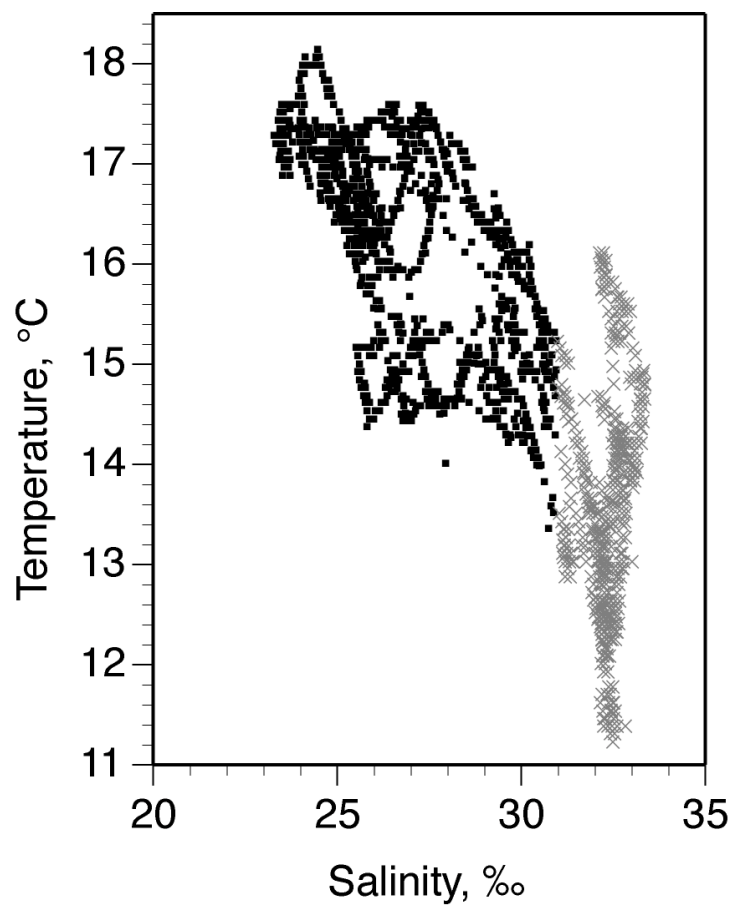

Fig. 1. T-S Diagram of Chesapeake Bay waters. salinity and total absorption is anticipated when high concentrations of colored dissolved organic matter and particulate detritus is often significant to absorption when the absorption is decoupled from phytoplankton concentration. This is the case for riverine and estuary conditions like those found in the Chesapeake Bay plume. The CDOM/detritus dominated waters can be expected to have a conservative and non-conservative fraction [1]. It is the non-conservative fraction that we expect to have a high coupling with salinity [2-4] due to photo-oxidation, coagulation, and dilution. The derived correlation dependencies based on hundreds of thousand data points shows significant correlation between salinity and optical absorption for certain water types.

Waters around the Chesapeake Bay Plume consist of at least three water masses; plume water with low salinity, cold-high salinity upwelled water, and warm-high salinity water. In a T-S diagram the plume water is distinct from the other two water masses which have high salinity but varying temperature (Fig. 1). For our analyses only the data with salinity less than $32 \%$ is used to represent waters likely to have a significant $\mathrm{CDOM} /$ detritus component for which correlation with salinity is likely. In cases where there is a freshwater source and only photo-degradation, local circulation, and dilution there is a strong linear relationship between salinity and CDOM [4].

\section{DERIVED RELATIONSHIPS}

Using absorption values from a Wetlabs Inc., absorption-attenuation meter AC-9 [5] a correlation matrix was produced. Unlike the normal linear relationship between salinity and gelbstoff absorption, the best fit for the total absorption was a quadratic expression. The higher order terms probably representing the non-linear mixing of the plume and the change from $\mathrm{CDOM} /$ detritus domination to one with phytoplankton absorption as well. The absorption data were used to estimate other optical properties such as scattering and backscattering coefficients and remote sensing optical reflectance. These derived relationships have applicability to remote sensing and optical modeling of the sea from space, which is discussed.

The absorption values had a high degree of covariance as indicated by the relationships below [Eqs. (1) and (2)] and in Figures 2 and 3. These results suggest that the exponential power would be in the range of 0.011 to 0.015 which is 


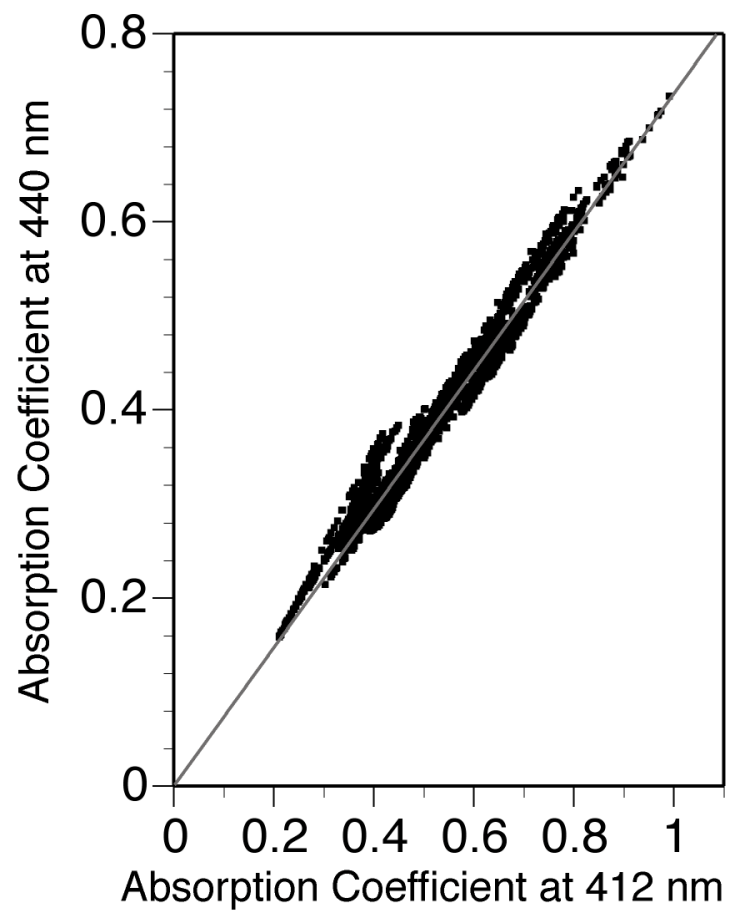

Figure 2. Regression between $a(440)$ and $a(412)$.

typical for mixed detritus and CDOM components. For the 2894 measurements of AC-9 data all absorption values at one channel strongly correlate with absorption values at other channels. The most significant correlations exist between channels 1 and 2 and channels 5 and 6 of AC-9 [5]. These correlations are shown below in the form of the following regressions:

$$
\begin{aligned}
& a(440)=0.7357 a(412), \quad r^{2}=0.973, \\
& a(555)=0.6910 a(532), \quad r^{2}=0.993 .
\end{aligned}
$$

In graphic form these regressions are presented in Figs. 2 and Fig. 3.

The analysis of data show strong regressional dependence of absorption coefficient at first 8 channes with the salinity. Beam attenuation coefficients also correlate with

Table 1. Coefficients in Eq. (3).

\begin{tabular}{|c|c|c|c|c|c|}
\hline $\mathrm{i}$ & $\lambda_{i}$ & $c_{0}$ & $c_{1}$ & $c_{2}$ & $r^{2}$ \\
\hline 1 & 412 & 8.43385 & 0.518907 & $8.38669 \mathrm{e}-3$ & 0.887 \\
2 & 440 & 6.84015 & 0.426817 & $6.95709 \mathrm{e}-3$ & 0.905 \\
3 & 488 & 4.14384 & 0.261913 & $4.30193 \mathrm{e}-3$ & 0.901 \\
4 & 510 & 3.41923 & 0.217590 & $3.58661 \mathrm{e}-3$ & 0.899 \\
5 & 532 & 2.68798 & 0.172211 & $2.85572 \mathrm{e}-3$ & 0.891 \\
6 & 555 & 1.85046 & 0.118938 & $1.97946 \mathrm{e}-3$ & 0.875 \\
7 & 650 & 0.96718 & 0.062665 & $1.04881 \mathrm{e}-3$ & 0.844 \\
8 & 676 & 2.63293 & 0.174582 & $2.95114 \mathrm{e}-3$ & 0.867 \\
\hline
\end{tabular}

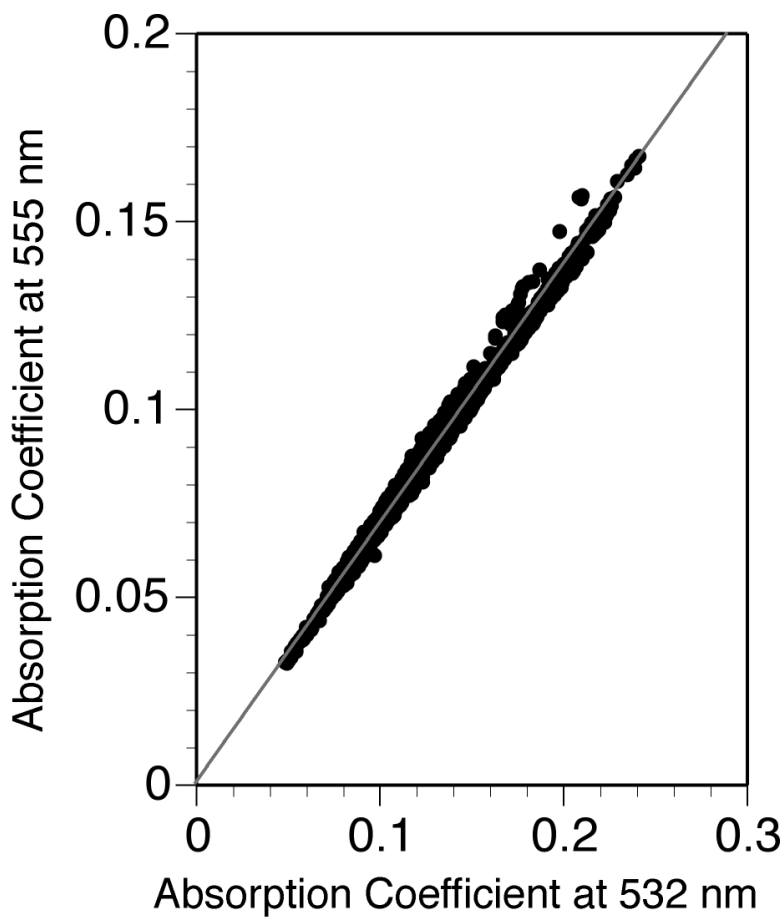

Figure 3. Regression between $a(555)$ and $a(532)$.

salinity but in a much weaker way. To produce working regressional relationships we tried different functional dependencies (power law, differences, and exponents). The best correlation were found for a polynomial fit of the second order:

$$
a\left(\lambda_{i}\right)=c_{0}\left(\lambda_{i}\right)-c_{1}\left(\lambda_{i}\right) S+c_{2}\left(\lambda_{i}\right) S^{2}, \quad i=1, \ldots, 8,
$$

here $a\left(\lambda_{i}\right)$ is an absorption coefficient for $i^{\text {th }}$ channel of AC-9 probe, $S$ is a salinity in \%o (promilles) and coefficients $C_{0}, C_{1}, C_{2}$ are given in Tab. 1. Regression (3) is valid for a salinity range between $23 \%$ and $32 \%$ o.

Table 1 shows the strongest correlation between salinity and total absorption was at $440 \mathrm{~nm}$. This is the wavelength used by Kirk [6] as a reference wavelength. There is undoubtedly covariance with detritus and chlorophyll that are functions of dilution and coastal mixing. The strong relationship; however, suggests that absorption can be derived from salinity using geospecific algorithms from remote sensing.

Analysis of Tab. 1 shows that it is possible to generalize relationships (3) for any arbitrary wavelength of light $\lambda$ lying between 412 and $676 \mathrm{~nm}$ (and, may be, between 400 and $700 \mathrm{~nm}$ ). The final regression is given as follows:

$$
a(\lambda)=c_{0}(\lambda)-c_{1}(\lambda) S+c_{2}(\lambda) S^{2}
$$

with the coefficients $c_{n}(\lambda), n=1,2,3$ given by Eqs. (5)-(7). 


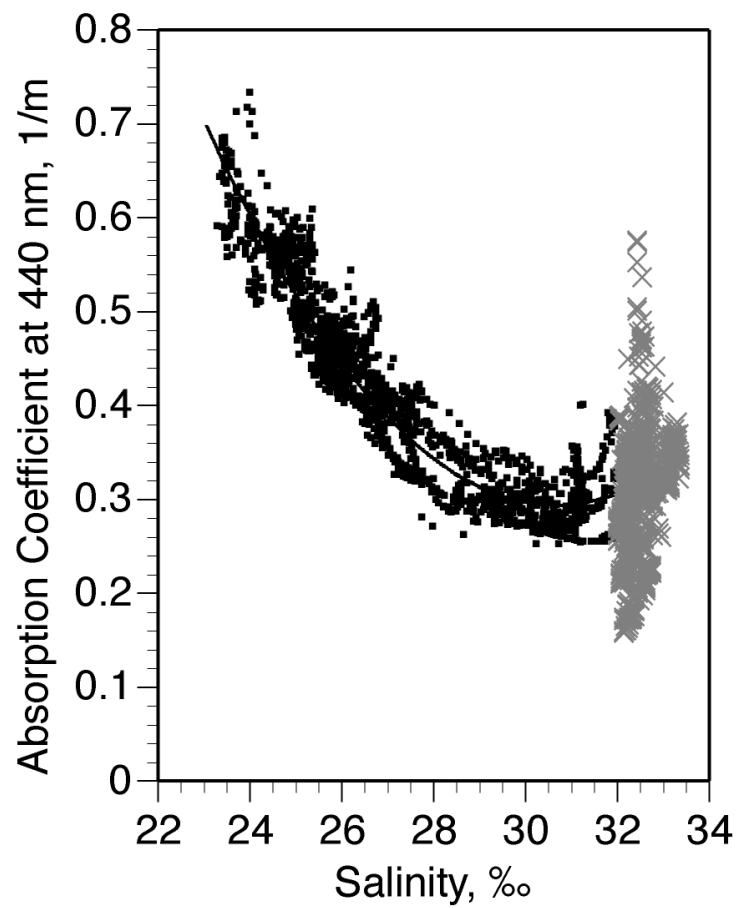

Figure 4. Regression between $a(440)$ and salinity.

$$
\begin{aligned}
c_{0}(\lambda) & =\left[112.0245\left(\frac{\lambda}{550}\right)^{3}-274.6267\left(\frac{\lambda}{550}\right)^{2}\right. \\
& \left.+195.6401\left(\frac{\lambda}{550}\right)-31.20033\right], \quad r^{2}=0.992, \\
c_{1}(\lambda) & =\left[8.129387\left(\frac{\lambda}{550}\right)^{3}-20.55429\left(\frac{\lambda}{550}\right)^{2}\right. \\
& \left.+15.59494\left(\frac{\lambda}{550}\right)-3.052657\right], \quad r^{2}=0.990, \\
c_{2}(\lambda) & =\left[0.1430164\left(\frac{\lambda}{550}\right)^{3}-0.3666161\left(\frac{\lambda}{550}\right)^{2}\right. \\
+ & \left.0.2855763\left(\frac{\lambda}{550}\right)-0.06003195\right], \quad r^{2}=0.989
\end{aligned}
$$

Equations (4)-(6) allow us to restore spectral profiles of absorption coefficient using salinity as input. These equations are supposed to be valid for spectral range $400 \leq \lambda \leq 700$ and salinity range $23 \%$ o $\leq S \leq 32 \%$.

To restore the whole set of spectral inherent properties, that include absorption and scattering coefficients and scattering phase function, we may use an algorithm proposed in [7] and based on a seawater optical model given in [8].

\section{CONCLUSION}

Analysis of database of absorption coefficients and salinity collected during Cope 97 experiment in Chesapeake Bay shows that there is strong correlation between salinity in the range between $23 \%$ and $32 \%$ and absorption coefficients in the first 8 channels of AC-9 probe. The derived regressions (4)-(7) allow us to restore the whole spectral profile of absorption coefficient using only salinity values. Further processing with the algorithm of Ref. [7] may also restore spectral scattering coefficient and spectral phase function of scattering.

\section{ACKNOWLEDGMENT}

The authors thank continuing support at the Naval Research Laboratory (NRL) through the Littoral Optical Environment (LOE 6640-09) program. This article represents NRL contribution NRL/PP/7331-00-0012.

\section{REFERENCES}

[1] O. V. Kopelevich, "The yellow substance in the ocean, according to optical data," Oceanology 22, 152-158 (1982).

[2] K. Kalle, "The problem of Gelbstoff in the sea," Oceanogr. Mar. Biol. Ann. Rev., 4, 91-104 (1966).

[3] N. V. Blough, O. C. Zafiriou, and J. Bonilla, "Optical absorption spectra of waters from the Orinoco River outflow; terrestrial input of colored organic matter to the Caribbean," JGR, 98, 2271-2278 (1983).

[4] M. S. Twardowki, and P. L. Donaghay, "Separating in situ and terrigenous sources of absorption by dissolved materials in coastal waters," in review JGR (2000).

[5] WETLabs Inc. AC-9 Documentation and Manual, June 1994, Philomath, Oregon, USA, 36 pp.

[6] J. T. O. Kirk, "Spectral absorption properties of natural waters: Contribution of the soluble and particulate fractions to light absorption in some inland waters of south-eastern Australia," Aust. J. Mar. Freshwater Res., 31, 287-296 (1980).

[7] V. I. Haltrin, "An algorithm to restore spectral signatures of all inherent optical properties of seawater using a value of one property at one wavelength," in: Proceedings of the Fourth International Airborne Remote Sensing Conference and Exhibition/21st Canadian Symposium on Remote Sensing, Published by ERIM International, Inc., Ann Arbor, MI, USA (1999), pp. I-680-687.

[8] V. I. Haltrin, "Chlorophyll-based model of seawater optical properties," Appl. Optics, 38, 6826-6832 (1999). 